Volume 3 Nomor 1 halaman 1 - 8

ISSN: 2089-6026

\title{
Identifikasi Jenis Kayu Menggunakan Support Vector Machine Berbasis Data Citra
}

\section{Wood Type Identification Using Support Vector Machine Based on Image Data}

\author{
A.A GEDE RAI GUNAWAN ${ }^{1 *}$, SRI NURDIATI $^{1}$, YANDRA ARKEMAN $^{2}$
}

\begin{abstract}
Abstrak
Identifikasi jenis kayu di Indonesia pada umumnya dilakukan secara manual, dengan cara memperhatikan pori kayu pada daerah penampang kayu menggunakan kaca pembesar atau mikroskop dengan pembesaran minimal 10 kali. Teknik komputerisasi belum banyak dilakukan terutama karena kurangnya penelitian di bidang ini dan sulitnya mendapatkan database kayu. Penelitian ini bertujuan mengembangkan sebuah sistem untuk mengklasifikasikan 4 jenis kayu yang diperdagangkan di Indonesia dengan metode support vector machine (SVM) berbasis citra. Teknik ekstraksi ciri yang digunakan adalah two-dimensional principal component analysis (2D-PCA). Sistem ini dapat mengidentifikasi kayu dalam waktu singkat sehingga mempercepat proses identifikasi jenis kayu. Hasil klasifikasi dari 120 kali percobaan dengan menggunakan 96 data citra dengan 4 jenis kayu menunjukkan akurasi terbaik sebesar $95.83 \%$ pada kernel Polinomial.
\end{abstract}

Kata kunci: Citra mikroskopis, Identifikasi jenis kayu, SVM

\begin{abstract}
Wood type identification in Indonesia usually has been done manually. The identification conducted by monitoring wood pore on wood longitudinal section using loupe or microscope with an enlargement at least 10 times. Computerized techniques have not been widely applied, due to the lack of research in this field and the difficulty to find wood databases. This research was aimed to develop a system to classify four types of wood traded in Indonesia, by using support vector machine based on image data. We used two-dimensional principal component analysis (2D-PCA) methods for extracted image data. This methods can identify the type of wood quite fast, so can speed up the identification of wood type. The result of classifying 96 image data with 4 types of wood shows that the best accuracy is $95.83 \%$ for Polinomial kernel.
\end{abstract}

Key words: microscopic images, SVM, wood type identification

\section{PENDAHULUAN}

Identifikasi jenis pohon di hutan dapat dengan mudah diketahui dengan memeriksa batang, bunga, buah dan daunnya. Namun setelah pohon ditebang, identifikasi jenis pohon menjadi sangat sulit karena harus mengenali ciri mikroskopis untuk identifikasinya. Salah satu ciri mikroskopis kayu adalah susunan pori, bentuk pori, frekuensi pori dan jari-jari yang hanya dapat dilihat dengan jelas menggunakan alat seperti mikroskop atau loupe dengan pembesaran minimal 10 kali. Metode identifikasi jenis kayu dapat dipelajari sebagai ilmu pengetahuan, namun kemampuan mengidentifikasi jenis kayu hanya dapat diperoleh melalui proses latihan yang cukup lama, berulang-ulang dan terus-menerus. Permasalahan yang timbul apabila petugas yang mengidentifikasi kayu belum terampil maka proses bisnis akan

\footnotetext{
${ }^{1}$ Departemen Ilmu Komputer, Fakultas Matematika dan Ilmu Pengetahuan Alam, Institut Pertanian Bogor, Bogor 16680

${ }^{2}$ Departemen Teknologi Industri Pertanian, Fakultas Teknologi Pertanian, Institut Pertanian Bogor, Bogor 16680

*Penulis korespondensi: Tel/Faks: 085248981915; Surel: rai_guns@yahoo.com
} 
membutuhkan waktu yang lebih lama dan tentunya akan menambah biaya (Mandang dan Pandit 2002). Sistem identifikasi jenis kayu sangat diperlukan untuk memberikan solusi pada permasalahan ini.

Penelitian menggunakan ciri pori kayu untuk menyelesaikan masalah identifikasi jenis kayu bangunan dan furniture dengan metode Neuro-Fuzzy telah dilakukan (Purba 2009). Penelitian tersebut mempunyai tingkat akurasi yang tinggi tapi memiliki kelemahan pada perlunya data training yang besar, belum berbasis citra dan hanya cocok digunakan jika contoh kayu yang digunakan untuk data uji sama dengan data latihnya. Penelitian identifikasi atau pengenalan wajah menggunakan two-dimensional principal component analysis (2DPCA) dan Support Vector Machine (SVM) mendapatkan hasil akurasi lebih tinggi yaitu 97.3\% dibandingkan menggunakan one-dimensional principal component analysis (1D-PCA) dan SVM yang mendapatkan hasil akurasi 95.7\% (Le dan Bui 2011). Metode 2D-PCA dan SVM berbasis citra untuk mengidentifikasi tanaman paku telah dilakukan dan memperoleh hasil yang baik dengan beragam percobaan (Maryana 2012).

Dalam penelitian ini, dilakukan pengenalan jenis kayu dengan menggunakan citra mikroskopis kayu sebagai pengenal cirinya dan mengekstraksi citra dengan menggunakan 2D-PCA. 2D-PCA mereduksi citra asli tanpa kehilangan informasi penting dari citra itu sendiri, sehingga dapat mempercepat proses pembelajaran. SVM digunakan untuk klasifikasi dari bentuk citra mikroskopis kayu. Sistem identifikasi jenis kayu ini diharapkan dapat membantu para petugas kehutanan dan pihak-pihak yang berkepentingan untuk mengidentifikasi jenis kayu secara cepat dan akurat.

Penelitian ini bertujuan mengembangkan sistem identifikasi jenis kayu berbasis citra dengan SVM dan mengevaluasi tingkat akurasi dari hasil identifikasi jenis kayu.

\section{METODE}

Metode pada penelitian ini terdiri atas beberapa tahapan proses yaitu, dimulai dari pengumpulan data menggunakan kamera mikroskopis. Tahapan praproses, pembagian data (data latih dan uji), ekstraksi ciri dengan metode 2D-PCA, pembelajaran, pengujian dan evaluasi dengan SVM menggunakan software Matlab 7.8, seperti ditunjukkan pada Gambar 1.

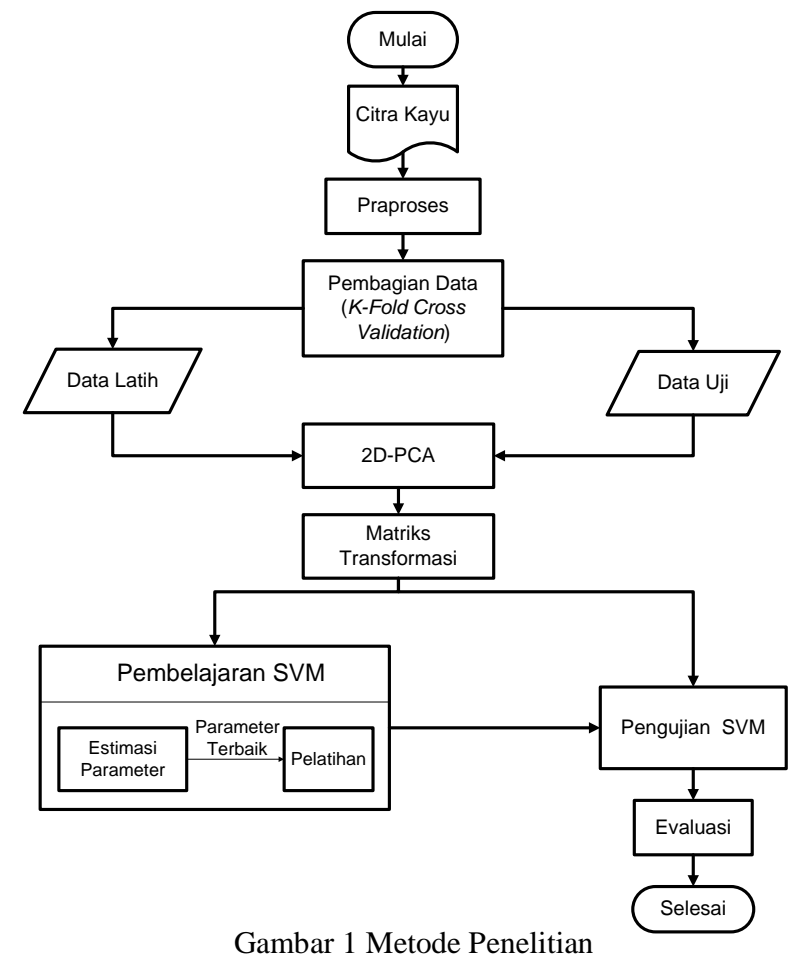




\section{Akuisisi Data Citra}

Bond dan Hamner (2002) mengelompokkan pengamatan permukaan kayu ke dalam tiga kategori referensi bidang geometris, yaitu : cross section, radial section, dan tangential section seperti ditunjukkan pada Gambar 2.

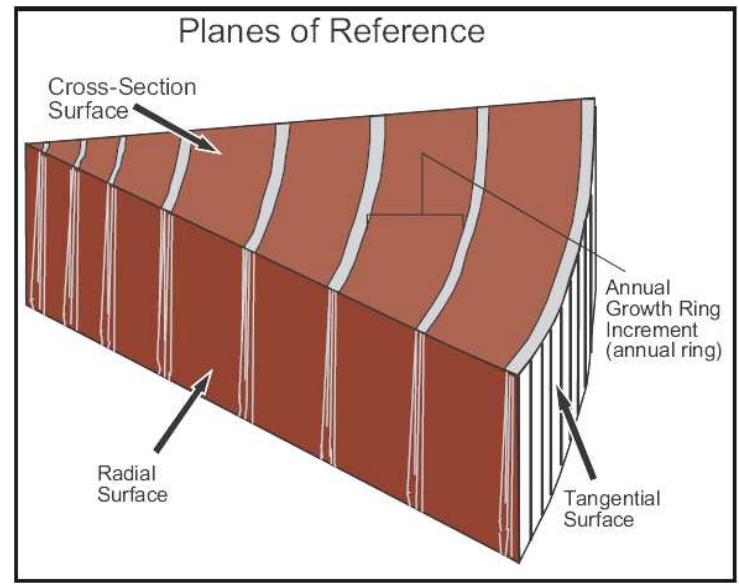

Gambar 2 Referensi tiga dimensi bidang geometris permukaan kayu

Data yang digunakan dalam penelitian ini berupa citra mikroskopis kayu sebanyak 96 citra yang berasal dari empat jenis kayu yang berbeda, masing-masing jenis kayu memberikan 24 citra yang berukuran 480 x 640 piksel. Ciri anatomi kayu dapat dilihat pada bidang cross section dengan cara memotong bidang kayu secara tegak lurus dengan arah pertumbuhan pohon atau bidang penampang kayu. Sebelum dilakukan pemotretan, daerah penampang kayu harus diiris terlebih dahulu dengan menggunakan cutter agar menghasilkan citra pori kayu yang bagus, seperti ditunjukkan pada Gambar 3.

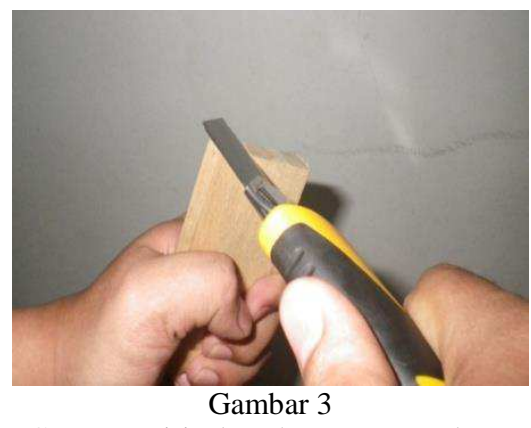

Cara mengiris daerah penampang kayu

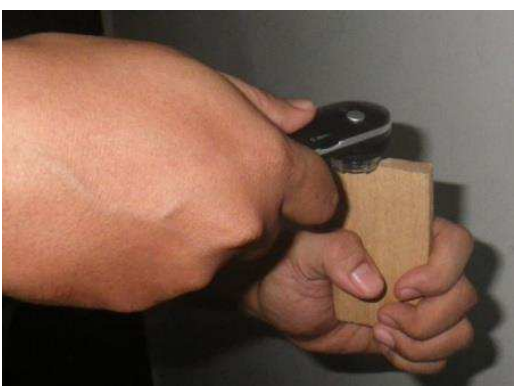

Gambar 4

Akuisisi citra mikroskopis kayu

Akuisisi citra mikroskopis kayu dilakukan dengan pemotretan sampel kayu yang berbeda jenisnya. Total data penelitian ini berjumlah 96 citra dari empat jenis kayu yang berbeda, masing-masing diambil 24 citra citra kayu berukuran 480 x 640 piksel. Dapat dilihat pada Gambar 4.

\section{Praproses}

Tahap Tahap awal praproses adalah mengubah ukuran citra menjadi 96 x 128 piksel dari ukuran asal 480 x 640 piksel dengan menggunakan fungsi pada program Matlab 7.8. Pada tahapan ini juga dilakukan pengubahan citra RGB menjadi citra grayscale yaitu mengubah citra RGB menjadi citra aras keabuan (Maryana 2012).

\section{Pembagian Data}

Pada tahapan ini citra dari masing-masing jenis kayu akan dibagi atau diacak menjadi subkelompok. Data sebanyak 96 citra dibagi menjadi data latih dan data uji menggunakan $K$ - 
Fold Cross Validation (Fu 1994), 72 citra sebagai data latih dan 24 citra sebagai data uji dengan kombinasi $k=4$.

\section{Ekstraksi Ciri}

Dilakukan dengan menggunakan metode 2D-PCA, bagian citra yang diekstraksi adalah citra mikroskopis kayu yang telah disamakan ukurannya. Hasil ekstraksi dengan 2D-PCA akan diperoleh komponen utama berupa vektor ciri yang diperoleh dengan mengambil nilai ciri yang terbesar yang dianggap mewakili dari kumpulan data yang ada. Vektor ciri ini diperoleh dari matriks kovarian untuk semua data latih yang ada. Langkah awal ekstraksi 2DPCA ini, semua citra data latih dicari rata-ratanya terlebih dahulu dan ilustrasi prosesnya dapat dilihat pada Gambar 5. Input citra mikroskopis kayu memiliki dimensi yang lebih kecil dibandingkan citra asli, sedangkan untuk keragaman informasi digunakan 50\% hingga 95\% kemiripan dari citra mikroskopis kayu (Yang dan Zhang 2004).

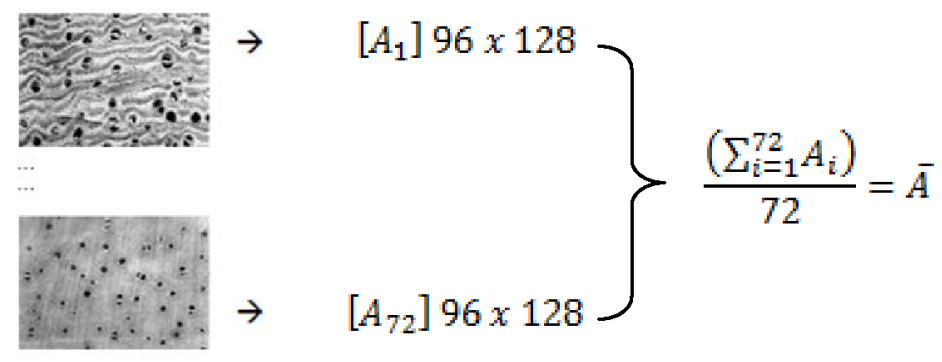

Gambar 5 Proses mencari rata-rata semua citra data latih

Setelah didapatkan matriks rataannya, kemudian dicari matriks kovarian untuk citra data latih dengan rumus sebagai berikut:

$$
G_{t}=\frac{1}{M} \sum_{j=1}^{M}\left(A_{j}-\bar{A}\right)^{T}\left(A_{j}-\bar{A}\right)
$$

Pada penelitian ini $G_{t}$ akan berukuran $n \times n$ dan $M$ adalah jumlah citra data latih sebanyak 72 citra. $A_{j}$ merupakan citra data latih yang digunakan dan $\bar{A}$ adalah rata-rata data dari semua data latih. Kemudian akan diperoleh akar ciri dari matriks kovarian tersebut yang mewakili karakteristik citra. Dari akar ciri tersebut dapat dicari vektor ciri yang akan menghasilkan matriks ciri sebagai input pembelajaran oleh SVM.

Rumus untuk mencari nilai ciri:

$\left|\lambda I-G_{t}\right|=0$

Rumus untuk mencari vektor ciri:

$(\lambda I-G t X)=0$

Keterangan:

$\lambda:$ Akar ciri

$I$ : Matriks diagonal

$G$ : Matriks kovarian

$X$ : Vektor ciri

\section{Matriks Transformasi}

Transformasi data latih dan data uji dilakukan untuk mengubah dimensi data yang akan digunakan. Data tersebut akan mengalami pengurangan dimensi karena proses reduksi vektor ciri (Yang dan Zhang 2004).

\section{Pembelajaran dengan Support Vector Machine}

Pembelajaran dengan menggunakan Support Vector Machine bersifat multi kelas, dapat dirancang untuk menyelesaikan permasalahan non-linear menggunakan bantuan fungsi kernel. Pada penelitian ini fungsi kernel yang digunakan adalah Radial Basis Function (RBF) dan 
Polinomial, seperti yang terlihat pada Gambar 6 (Christianini dan Taylor 2000).
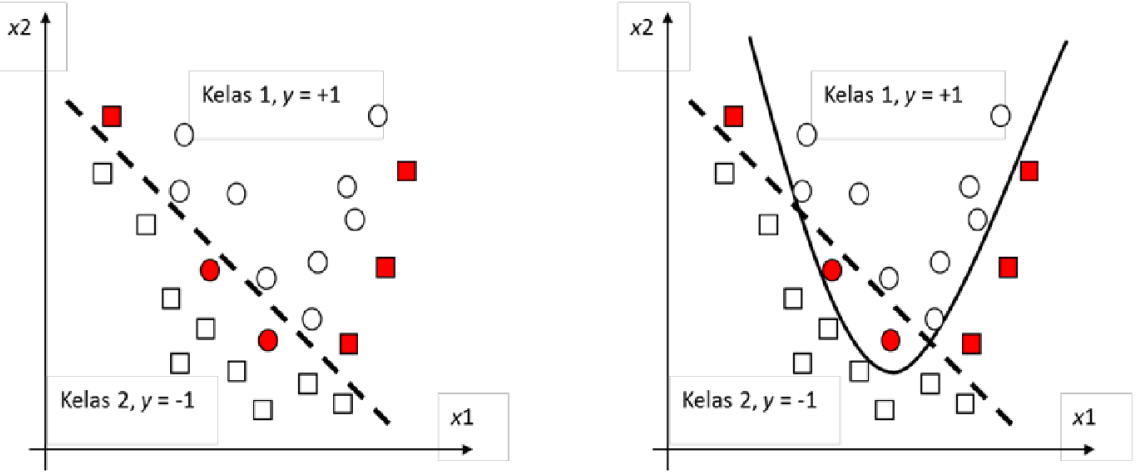

Gambar 6 Ilustrasi permasalahan SVM non-linear

Di dalam penelitian ini dilakukan beberapa percobaan untuk memperoleh tingkat akurasi yang baik dengan menggunakan fungsi kernel, yaitu:

1. Percobaan fungsi kernel RBF menggunakan parameter sigma $(\sigma)=1,5,10,15,20,25,30$, 35, 40, 45 dan 50 dengan ekstraksi ciri 50\%-95\%.

2. Percobaan fungsi kernel Polinomial menggunakan parameter $d=1,2,3,4$ dengan ekstraksi ciri $50 \%-95 \%$.

\section{Analisis dan Evaluasi}

Evaluasi dilakukan dengan menggunakan Confusion matrix yang merupakan sebuah tabel, terdiri atas banyaknya baris data uji yang diprediksi benar dan tidak benar oleh sistem klasifikasi untuk menentukan kinerja suatu sistem klasifikasi (Tan et al 2005). Proses pelatihan dan pengujian menggunakan pembelajaran SVM yang dilakukan mendapatkan hasil tingkat akurasi atau keberhasilan pengenalan klasifikasi jenis kayu dan tingkat kesalahan dalam pengenalan citra mikroskopis kayu pada masing-masing kelas. Akurasi dihitung berdasarkan data uji pada proses empat fold cross validation.

$$
\text { Akurasi }=\frac{\text { Jumlah klasifikasi yang benar }}{\text { Jumlah semua data uji }} \times 100 \%
$$

\section{HASIL DAN PEMBAHASAN}

\section{Data Citra dan Praproses}

Sampel hasil dari akuisisi citra mikroskopis kayu pada penelitian ini dapat dilihat pada Gambar 7.

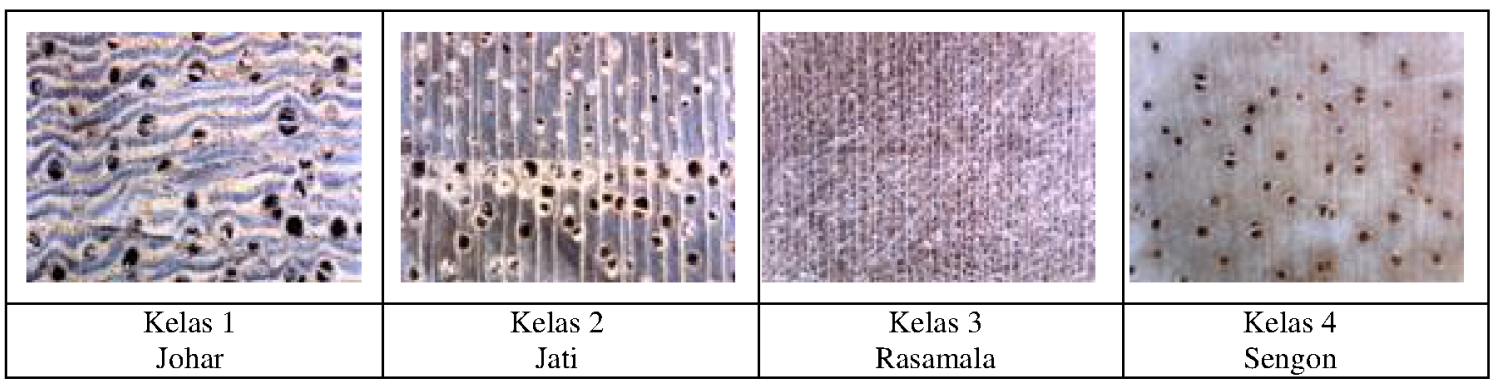

Gambar 7 Citra mikroskopis kayu

Citra kayu berukuran 96 x 128 piksel diubah dari citra RGB menjadi citra grayscale, seperti ditunjukkan pada Gambar 8. 


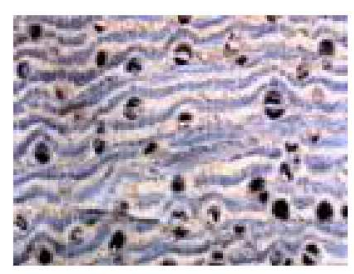

Citra RGB

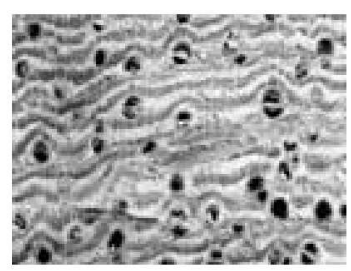

Citra Grayscale

Gambar 8 Hasil praproses

\section{Pembagian Data Latih dan Data Uji}

Data yang digunakan dalam penelitian ini sebanyak 96 citra. Pembagian data latih dan data uji menggunakan $K$-Fold Cross Validation yaitu dengan $K=4$ seperti dapat dilihat pada Gambar 9.
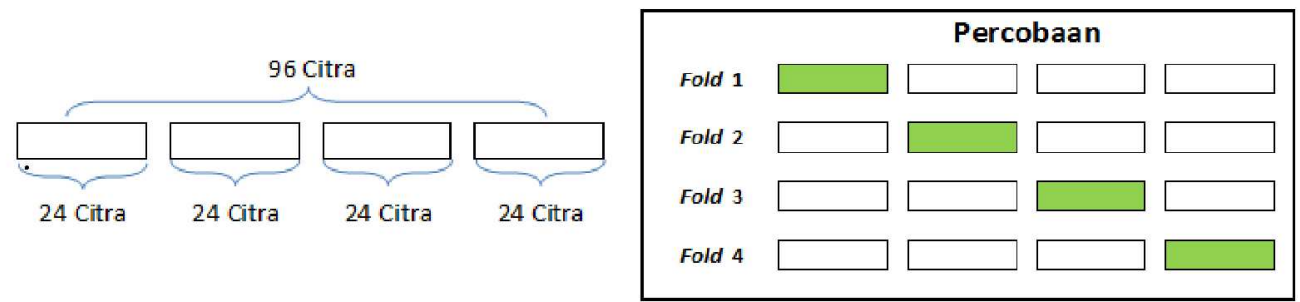

Gambar 9 Pembagian data latih dan data uji

\section{Ekstraksi Ciri}

Citra kayu berukuran 96 × 128 piksel diekstraksi dengan menggunakan metode 2D-PCA dengan nilai akar ciri 50\% sampai dengan 95\% untuk mereduksi ukuran dimensi dari citra, seperti ditunjukkan pada Tabel 1.

Tabel 1 Hasil Ektraksi Ciri

\begin{tabular}{cccc}
\hline Ekstraksi Ciri & Dimensi & Ekstraksi Ciri & Dimensi \\
\hline $50 \%$ & $96 \times 19$ & $80 \%$ & $96 \times 42$ \\
$60 \%$ & $96 \times 25$ & $85 \%$ & $96 \times 49$ \\
$70 \%$ & $96 \times 32$ & $90 \%$ & $96 \times 59$ \\
$75 \%$ & $96 \times 37$ & $95 \%$ & $96 \times 76$ \\
\hline
\end{tabular}

\section{Matriks Transformasi}

Matriks hasil transformasi dengan ukuran $96 \times 19\left(\boldsymbol{C}_{96 \times 19}\right)$, diperoleh dari perkalian matriks citra asli greyscale ukuran $96 \times 128\left(\boldsymbol{A}_{96 \times 128}\right)$ dengan matriks ciri ukuran $128 \times 19$ $\left(B_{128 \times 19}\right)$.

\section{Pembelajaran Metode SVM}

\section{Menggunakan kernel RBF}

Percobaan menggunakan fungsi kernel RBF, parameter sigma $(\sigma)=35,40,45$ dan 50 dengan ekstraksi ciri 60\% menghasilkan tingkat akurasi tertinggi, yaitu 94.79\%. Jumlah data yang salah diklasifikasikan sebanyak 11 data dari 96 data. Pada saat ekstraksi ciri $80-95 \%$ terjadi penurunan tingkat akurasi, hal ini terjadi karena sistem tidak dapat membaca dengan baik ciri-ciri dominan yang terdapat pada citra mikroskopis kayu. Hasil percobaan seperti ditunjukkan pada Gambar 10. 


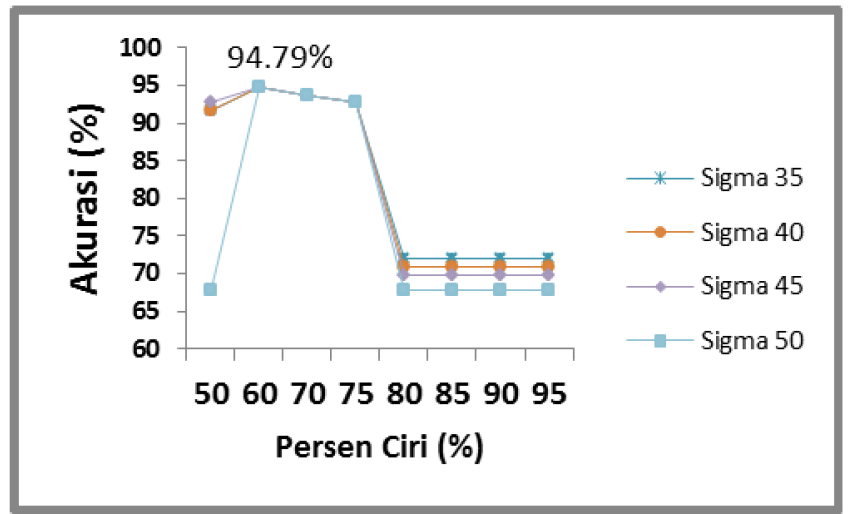

Gambar 10 Akurasi tertinggi kernel RBF

Kesalahan klasifikasi jenis kayu oleh sistem dari percobaan menggunakan kernel RBF parameter sigma $=35,40,45$ dan 50 dengan ekstraksi ciri $60 \%$ dijabarkan menggunakan confusion matrix ditunjukkan pada Tabel 2. Tabel tersebut menunjukkan klasifikasi pada kelas 1 (Kayu Johar) dan kelas 2 (Kayu Jati) terklasifikasi 100\% sedangkan kelas 3 (Kayu Rasamala) ada tiga data yang terindentifikasi kelas 4 oleh prediktor dan kelas 4 (Kayu Sengon) ada delapan data yang teridentifikasi kelas 3 oleh prediktor. Ini menandakan bahwa kelas 3 dan kelas 4 terdapat kesamaan pola citra data.

Tabel 2 Confusion matrix percobaan kernel $\mathrm{RBF}$ dengan parameter sigma $(\sigma)=35,40,45$ dan 50

\begin{tabular}{ccccc}
\hline \multirow{2}{*}{ AKTUAL } & \multicolumn{4}{c}{ PREDIKSI } \\
\cline { 2 - 5 } & Kelas 1 & Kelas 2 & Kelas 3 & Kelas 4 \\
\hline Kelas 1 & 24 & 0 & 0 & 0 \\
Kelas 2 & 0 & 24 & 0 & 0 \\
Kelas 3 & 0 & 0 & 23 & 1 \\
Kelas 4 & 0 & 0 & 3 & 21 \\
\hline
\end{tabular}

\author{
Keterangan: \\ Kelas $1=$ Kayu Johar \\ Kelas 2 = Kayu Jati \\ Kelas 3 = Kayu Rasamala \\ Kelas 4 = Kayu Sengon
}

2. Menggunakan fungsi kernel Polinomial.

Percobaan menggunakan fungsi kernel Polinomial, parameter orde 1 dengan ekstraksi ciri $60 \%$ sampai dengan $75 \%$ menghasilkan tingkat akurasi tertinggi, yaitu 95.83\%. Jumlah data yang salah diklasifikasikan sebanyak empat data dari 96 data. Pada saat ekstraksi ciri 85 - 95\% terjadi penurunan tingkat akurasi, akan tetapi penurunan tingkat akurasi ini tidak terjadi secara drastis seperti halnya pada kernel RBF. Hasil percobaan seperti ditunjukkan pada Gambar 11.

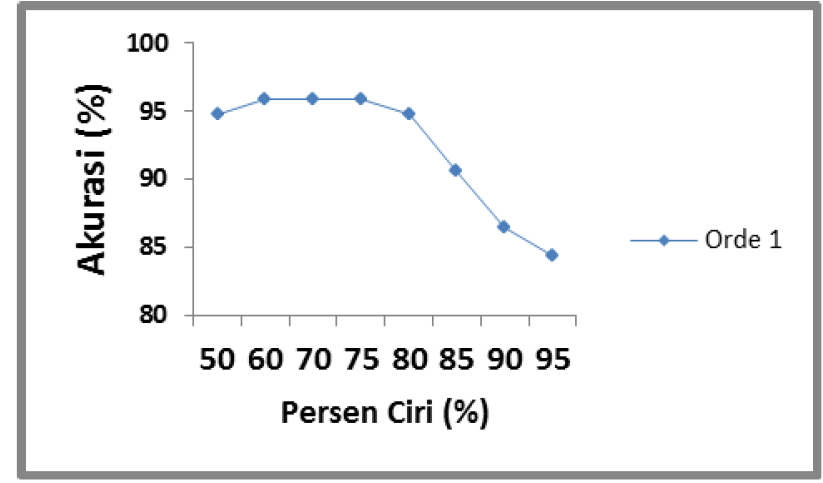

Gambar 11 Akurasi tertinggi kernel polinomial

Kesalahan yang dihasilkan dari percobaan menggunakan kernel Polinomial parameter $d=1$ dengan ekstraksi $60 \%$ sampai dengan $75 \%$ dijabarkan menggunakan confusion matrix, ditunjukkan pada Tabel 3. 
Tabel 3 Confusion matrix percobaan kernel polinomial dengan parameter orde $(d)=1$

\begin{tabular}{rcccc}
\hline \multirow{2}{*}{ AKTUAL } & \multicolumn{4}{c}{ PREDIKSI } \\
\cline { 2 - 5 } & Kelas 1 & Kelas 2 & Kelas 3 & Kelas 4 \\
\hline Kelas 1 & 24 & 0 & 0 & 0 \\
Kelas 2 & 0 & 24 & 0 & 0 \\
Kelas 3 & 0 & 0 & 23 & 1 \\
Kelas 4 & 0 & 0 & 3 & 21 \\
\hline
\end{tabular}

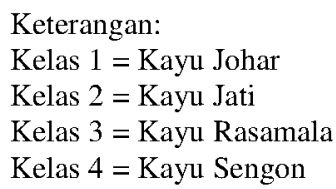

Tabel 3 menunjukkan klasifikasi pada kelas 1 (Kayu Johar) dan kelas 2 (Kayu Jati) teridentifikasi $100 \%$ sedangkan pada kelas 3 (Kayu Rasamala) ada satu data yang teridentifikasi kelas 4 (Kayu Sengon) pada kelas prediktor dan pada kelas 4 (Kayu Sengon) ada tiga data yang teridentifikasi kelas 3 (Kayu Rasamala) pada kelas prediktor.

\section{SIMPULAN DAN SARAN}

Penelitian ini telah berhasil mengembangkan sistem identifikasi jenis kayu menggunakan metode 2D-PCA dan SVM dengan tingkat akurasi mampu mencapai lebih dari 95\% pada kernel Polinomial dengan ekstraksi ciri $60 \%$ sampai dengan $70 \%$. Sistem ini dapat dikembangkan dengan menggunakan kamera mikroskopis yang memiliki kemampuan perbesaran yang lebih tinggi. Teknik ekstraksi ciri dan metode klasifikasi yang lain juga dapat dicoba untuk memperoleh tingkat akurasi yang lebih baik serta mengembangkannya dalam bentuk perangkat mobile.

\section{DAFTAR PUSTAKA}

Bond B, Hamner P. 2002. Wood Identification for Hardwood and Soft wood Species. Tennesse (US): Department of Forestry, Wildlife and Fisheries The University of Tennessee. PB1692-1.5M-2/02.

Christianini Nello dan Taylor J.S. 2000. An Introduction to Support Vector Machines and Other Kernel-based Learning Methods. Cambridge University Press.

Fu L. 1994. Neural Network in Computer Intelligence. Singapura: McGraw Hill. ISBN: 0071133194.

Le Thai Hoang, Bui Len (2011), Face Recognation Based on SVM and 2D-PCA, International Journal of Signal Processing, Image Processing and Pattern Recognation, Vol.4. No.3. Page 85-93.

Mandang YL, Pandit IKN. 2002. Seri Manual : Pedoman Identifikasi Jenis Kayu Lapangan. Bogor (ID): PROSEA.

Maryana S. 2012. Pemodelan Support Vector Machine Untuk Identifikasi Jenis Tanaman Paku Berdasarkan Citra Spora Dalam Ruang Eigen. [Tesis]. Bogor (ID): Intitut Pertanian Bogor.

Purba FRBr. 2009. Rekayasa Sistem Neuro-Fuzzy Untuk Identifikasi Jenis Kayu Bangunan dan Furniture. Yogyakarta (ID): SNATI UII, ISSN 1907.

Tan et al 2005. Introduction to Data Mining. US: Addison Wesley.

Yang dan Zhang. 2004. Two-Dimensional PCA: A New Approach to Appearance-Based Face Representation and Recognition. IEEE on Transactions on Pattern Analysis and Machine Intelligence. Vol. 26, No.1. 